\title{
Ambulatory and home blood pressure monitoring: gaps between clinical guidelines and clinical practice in Singapore
}

This article was published in the following Dove Press journal:

International Journal of General Medicine

3 July 2017

Number of times this article has been viewed

\author{
Sajita Setia' \\ Kannan Subramaniam ${ }^{2}$ \\ Boon Wee Teo ${ }^{3}$ \\ Jam Chin Tay ${ }^{4}$ \\ 'Chief Medical Office, Medical Affairs, \\ Pfizer Pte Ltd, Singapore; ${ }^{2}$ Global \\ Medical Affairs, Asia Pacific Region, \\ Pfizer Australia, West Ryde, New \\ South Wales, Australia; ${ }^{3}$ Department \\ of Medicine, Yong Loo Lin School \\ of Medicine, National University of \\ Singapore, Singapore; ${ }^{4}$ Department \\ of General Medicine, Tan Tock Seng \\ Hospital, Singapore
}

Purpose: Out-of-office blood pressure (BP) measurements (home blood pressure monitoring [HBPM] and ambulatory blood pressure monitoring [ABPM]) provide important additional information for effective hypertension detection and management decisions. Therefore, outof-office BP measurement is now recommended by several international guidelines. This study evaluated the practice and uptake of HBPM and ABPM among physicians from Singapore.

Materials and methods: A sample of physicians from Singapore was surveyed between 8 September and 5 October 2016. Those included were in public or private practice had been practicing for $\geq 3$ years, directly cared for patients $\geq 70 \%$ of the time, and treated $\geq 30$ patients for hypertension per month. The questionnaire covered six main categories: general BP management, BP variability (BPV) awareness/diagnosis, HBPM, ABPM, BPV management, and associated training needs.

Results: Sixty physicians (30 general practitioners, 20 cardiologists, and 10 nephrologists) were included (77\% male, 85\% aged 31-60 years, and mean 22-year practice). Physicians recommended HBPM and ABPM to $81 \%$ and $27 \%$ of hypertensive patients, respectively. HBPM was most often used to monitor antihypertensive therapy ( $88 \%$ of physicians) and $97 \%$ thought that ABPM was useful for providing information on BPV. HBPM instructions often differed from current guideline recommendations in terms of frequency, number of measurements, and timing. The proportion of consultation time devoted to discussing HBPM and BPV was one-quarter or less for $73 \%$ of physicians, and only $55 \%$ said that they had the ability to provide education on HBPM and BPV. Patient inertia, poor patient compliance, lack of medical consultation time, and poor patient access to a BP machine were the most common challenges for implementing out-of-office BP monitoring.

Conclusion: Although physicians from Singapore do recommend out-of-office BP measurement to patients with hypertension, this survey identified several important gaps in knowledge and clinical practice.

Keywords: hypertension, blood pressure monitoring, blood pressure variability, guidelines

\section{Introduction}

Clinic BP is the current gold standard for the screening, diagnosis, and treatment of hypertension. ${ }^{1}$ However, this provides only a single assessment under conditions that can influence the parameter being measured. ${ }^{2}$ Therefore, there is increasing recognition that out-of-office blood pressure (BP) measurements, such as home blood pressure monitoring (HBPM) and ambulatory blood pressure monitoring (ABPM), provide important additional information on which to base effective decisions about the detection and management of hypertension. As a result, out-of-office BP measurement is now recommended by several international guidelines, most of which advocate the
Medical Affairs, Pfizer Pte Ltd, 80 Pasir Panjang Road, \#16-8I/82, Mapletree Business City, Singapore II 7372 ,

Singapore

Tel +6564038754

Fax +6567224188

Email sajita.setia@pfizer.com 
complementary use of HBPM and ABPM. ${ }^{1,3,4}$ In clinical practice, out-of-office measurement tools are often used to distinguish patients who have elevated clinic BP but with normal readings during usual daily activities ("white-coat" hypertension) or those with normal clinic BP but with elevated readings outside the clinic ("masked" hypertension). ${ }^{5}$ In addition, there is increasing recognition of the role of blood pressure variability (BPV) in contributing to overall cardiovascular risk. ${ }^{6}$ This further highlights the importance of monitoring and managing BPV, something that cannot be achieved with clinic BP measurements alone.

Guidelines from the UK, ${ }^{3}$ Japanese Society of Hypertension, ${ }^{4}$ and European Society of Hypertension/European Society of Cardiology ${ }^{1}$ all include ABPM- and HBPM-based definitions for diagnosing hypertension (Table 1). The European guidelines provide detailed guidance on the use of outof-office BP measurement for diagnostic purposes, ${ }^{1}$ while ABPM and HBPM are endorsed to the greatest extent in the Japanese Society of Hypertension (JSH) document. ${ }^{4}$ These guidelines advocate the use of HBPM for diagnosing hypertension in all patients, with ABPM used if necessary, allowing differentiation between patients with white-coat, masked, or persistent hypertension. ${ }^{4}$ Both the JSH and National Institute for Health and Care Excellence (NICE) guidelines suggest that out-of-office BP monitoring can be used to assess BPV and to determine 24-hour BP control (Table 1). ${ }^{3,4}$ In contrast, US guidelines from the Eighth Joint National Committee (JNC8) make little mention of home or ambulatory BP measurements. ${ }^{7}$

Singaporean Ministry of Health $(\mathrm{MOH})$ clinical practice guidelines for hypertension were last produced in 2005.8 Although these did define a home BP cut-off for the diag- nosis of hypertension (average $>135 / 85 \mathrm{mmHg}$ ), there was no explicit recommendation for HBPM, and ABPM was recommended only in specific clinical situations. In addition, the guidelines are now stated as withdrawn because they have not been updated for $>5$ years since publication. ${ }^{8}$ This absence of updated local guidance means that the practice and uptake of out-of-office BP monitoring in Singapore may be inconsistent, both between physicians and in terms of compliance with international guidelines.

The aim of this study was to evaluate the practice and uptake of HBPM and ABPM among physicians from Singapore.

\section{Materials and methods}

A random sample of physicians from Singapore was included in this cross-sectional survey that was conducted from September 8 to October 5, 2016. Surveys were conducted according to the globally accepted standards of good clinical practice (as defined in the International Conference on Harmonisation [ICH] E6 Guidelines for Good Clinical Practice, May 1, 1996), in agreement with the latest version of the Declaration of Helsinki, and in accordance with the local internal and external regulations. Included physicians (general practitioners [GPs], cardiologists, and nephrologists) were recruited using random sampling with a focus on obtaining a geographically representative sample (from the North, Central, North East, East, and West of the country).

\section{Study sample}

A short screening questionnaire was administered via telephone to determine physician eligibility and willingness to participate in the survey (see online Supplementary material

Table I Blood pressure monitoring-related guidance from international guidelines commonly referred to in Singapore

\begin{tabular}{|c|c|c|c|}
\hline Parameter & NICE $20 I^{3}$ & ESH/ESC 2013' & JSH $2014^{4}$ \\
\hline Hypertension (ABPM) & $\begin{array}{l}\text { Daytime average } B P: \geq \mid 35 / \geq 85 \\
\text { mmHg* }\end{array}$ & $\begin{array}{l}\text { Daytime/awake BP: } \geq 135 / 85 \mathrm{mmHg} \\
\text { Night-time/asleep BP: } \geq 120 / 70 \mathrm{mmHg} \\
\text { 24-hour BP: } \geq 130 / \geq 80 \mathrm{mmHg}\end{array}$ & 24-hour BP: $\geq 130 / 80 \mathrm{mmHg}$ \\
\hline Hypertension (HBPM) & $\mathrm{BP} \geq 135 / \geq 85 \mathrm{mmH} \mathrm{g}^{*}$ & $\mathrm{BP} \geq 135 / \geq 85 \mathrm{mmHg}$ & $\mathrm{BP} \geq 135 / 85 \mathrm{mmHg} \ddagger$ \\
\hline $\begin{array}{l}\text { White-coat } \\
\text { hypertension }\end{array}$ & $\begin{array}{l}\text { A discrepancy of }>20 / 10 \mathrm{mmHg} \\
\text { between clinic BP and average } \\
\text { daytime ABPM or average HBPM }\end{array}$ & $\begin{array}{l}\text { Elevated clinic } \mathrm{BP}(\geq \mid \mathrm{I} 0 / 90 \mathrm{mmHg}) \text { at } \\
\text { multiple visits but normal } \mathrm{BP}(<\mathrm{I0} / 85 \\
\mathrm{mmHg}) \text { on either } \mathrm{ABPM} \text { or } \mathrm{HBPM}\end{array}$ & $\begin{array}{l}\text { Clinic } B P \geq 140 / 90 \mathrm{mmHg} \text { with } \mathrm{BP}<135 / 85 \\
\mathrm{mmHg} \text { on } \mathrm{HBPM} \text { or mean } 24 \text {-hour } B P \\
<130 / 80 \mathrm{mmHg} \text { on } \mathrm{ABPM}\end{array}$ \\
\hline Masked hypertension & ND & $\begin{array}{l}\text { Clinic } B P<130 / 85 \mathrm{mmHg} \text { with BP } \\
\geq 140 / 90 \mathrm{mmHg} \text { on ABPM or HBPM }\end{array}$ & $\begin{array}{l}\text { Clinic } B P<140 / 90 \mathrm{mmHg} \text { with } \mathrm{BP}>135 / 85 \\
\mathrm{mmHg} \text { on } \mathrm{HBPM} \text { or mean } 24 \text {-hour BP } \\
>130 / 80 \text { on ABPM }\end{array}$ \\
\hline 24-hour BP control & $\begin{array}{l}\text { Daytime average } \mathrm{BP} \text { targets on } \\
\text { ABPM or HBPM of }<135 / 85 \mathrm{mmHg} \\
\text { (age }<80 \text { years) or }<145 / 85 \mathrm{mmHg} \\
\text { (age } \geq 80 \text { years) }\end{array}$ & $\begin{array}{l}\text { Lists methods to improve adherence } \\
\text { to physicians' recommendations as a } \\
\text { way of improving BP control }\end{array}$ & $\begin{array}{l}\text { BP control over } 24 \text { hours is important } \\
\text { HBPM and ABPM can be used to assess } \\
\text { diurnal changes in BP }\end{array}$ \\
\hline
\end{tabular}

Notes: *In addition to clinic BP $\geq 140 / 90 \mathrm{mmHg}$ (use ABPM first, then HBPM if ABPM not tolerated); $\neq$ If clinic BP differs from home BP, the HBPM-based diagnosis should take priority.

Abbreviations: ABPM, ambulatory blood pressure monitoring; BP, blood pressure; ESC, European Society of Cardiology; ESH, European Society of Hypertension; HBPM, home blood pressure monitoring; JSH, Japanese Society of Hypertension; ND, not discussed; NICE, National Institute for Health and Care Excellence. 
for full details). Inclusion criteria were public (restructured) or private practice, practicing for $\geq 3$ years, $\geq 70 \%$ of time spent in directly involved in patient care, and treatment of $\geq 30$ patients for hypertension each month, and providing verbal informed consent to participate. The physician survey was outside the scope of human biomedical research, as defined by the Bioethics Advisory Committee, $\mathrm{MOH}$, Singapore. ${ }^{9}$ The survey was carried out after approval from Pfizer's committee managing customer engagement programs (CEPs). These programs are managed by a dedicated team that ensures that all adverse events (AEs) from CEPs are being reported properly and on a timely basis to safety for processing. The organization carrying out the survey (Kantar Health) was trained in AE reporting.

\section{Survey}

Quantitative surveys were conducted using a combination of online (computer-assisted web interviews [CAWIs]) and face-to-face (computer-assisted personal interviews [CAPIs]) interviews, each of which took $\sim 30$ minutes. The CAWI was a self-administered interview, and CAPI was administered by a specialized health care interviewer. Two interviewers conducted all interviews after receiving identical training on the questionnaire and process. After providing a brief introduction to the overall objectives of the research, the survey included a series of questions covering six main categories:

1. General BP management: eight questions relating to hypertension guidelines in practice, target BP for different patient groups, proportions of patients achieving target $\mathrm{BP}$, and commonly prescribed antihypertensive agents.

2. BPV awareness and diagnosis: three questions relating to the definition of BPV and the diagnosis of BPV (e.g., cut-off points, techniques, and tools).

3. HBPM: twelve questions relating to how and why physicians recommend HBPM.

4. ABPM: five questions relating to how and why physicians recommend $\mathrm{ABPM}$.

5. BPV management: three questions relating to current practice around estimating BPV, what physicians recommend, and the gaps/unmet needs in this area.

6. Training needs of health care professionals regarding BPV: nine questions relating to the extent of any existing training, the need for further education/training on BPV, and what type/frequency of training would be suggested.

Interviewers recorded responses to all questions from each physician; these were then collated and tabulated for analysis. A full copy of the study questionnaire is provided in the online supplementary material.

This paper focuses on findings from sections 3 and 4 of the questionnaire, and on relevant parts of section 6 . Findings relating to hypertension and BPV management practices in Singapore are the subject of a separate manuscript.

\section{Statistical analysis}

Physician responses to the questionnaires were summarized using descriptive statistics (as numbers and percentages). Raw data in SPSS and Dimensions (tables object module) were used for tabulation; SPSS raw data were converted into dimensions format viz. mdd/ddf format. The processed tables were then checked against frequencies taken from original raw data received. Categorical variables were expressed as percentages, and continuous variables were expressed as mean values. Statistical analysis was performed using the SPSS Statistics 20.

\section{Results \\ Sample and response rate}

Of 215 physicians contacted about the survey, a total of 60 (30 GPs, 20 cardiologists, and 10 nephrologists) were included in the final sample (response rate $28 \%$ ). The flow of participants is shown in Figure 1. The majority of physicians were male $(77 \%$ overall, $83 \%$ of GPs, $80 \%$ of cardiologists, and $50 \%$ of nephrologists), and the majority of GPs and cardiologists were aged $41-60$ years $(67 \%$ and $70 \%$, respectively). Nephrologists tended to be younger, with $70 \%$ aged $31-40$ years, while there were six GPs (20\%) and three cardiologists $(15 \%)$ aged $>60$ years. The mean postresidency practice duration was 22 years overall (25 years for GPs, 22 years for cardiologists, and 12 years for nephrologists), and the mean number of patients with hypertension treated each month was 138, 214, and 140 for GPs, cardiologists, and nephrologists, respectively. Respondents were from the Central $(n=30 ; 50 \%)$, North-East $(n=13 ; 22 \%)$, North $(n=12$; $20 \%)$, or West $(n=5 ; 8 \%)$ areas of Singapore. Practice setting varied by specialty, with nephrologists more likely to be in private practice, while specialists (cardiologists and nephrologists) saw the most patients with hypertension and comorbidities (Table 2).

\section{Home BP monitoring}

Almost all physicians surveyed (98\%) stated that they recommend HBPM to their patients with hypertension. Overall, $81 \%$ of hypertensive patients were recommended to measure home BP ( $85 \%$ of those treated by cardiologists, $85 \%$ by nephrologists, and $76 \%$ by GPs). The most common reason 


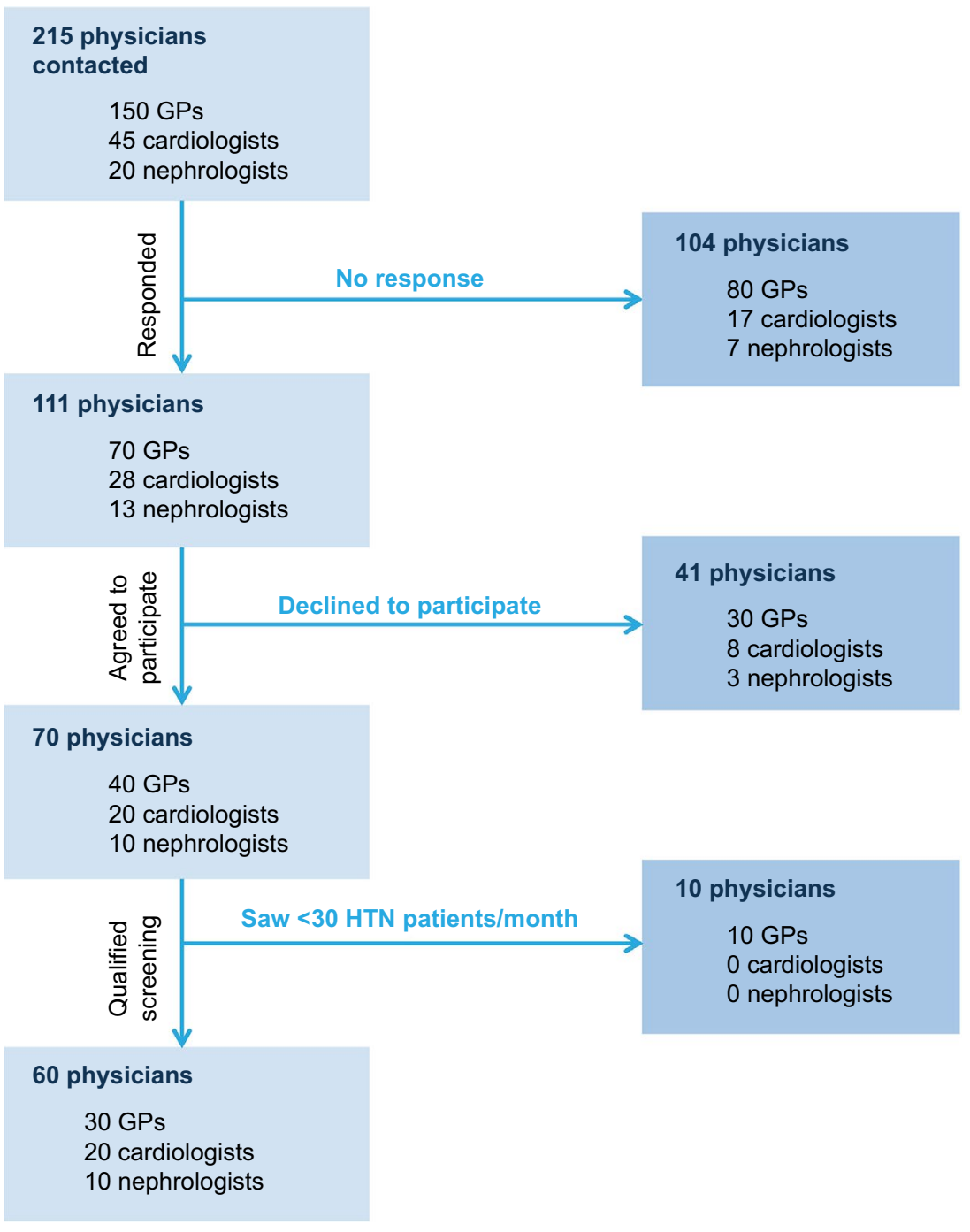

Figure I Physician recruitment.

Abbreviations: GPs, general practitioners; HTN, hypertension.

for recommending HBPM overall (88\%), and for GPs (93\%) and cardiologists (90\%), was to evaluate the efficacy of antihypertensive drugs; for nephrologists, the most common reason to recommend HBPM was for hypertension management using HBPM (90\%). Around three-quarters of respondents stated that they used HBPM to monitor BPV $(75 \%$ overall, $79 \%$ of GPs, $70 \%$ of cardiologists, and $70 \%$ of nephrologists). Use of HBPM to evaluate cardiovascular risk was uncommon ( $10 \%$ overall) but highest for cardiologists $(20 \%$ vs 3\% of GPs and $10 \%$ of nephrologists). Measurements of both morning and evening home $\mathrm{BP}$ were seen as important for treating hypertension by $77 \%$ of physicians ( $73 \%$ of GPs, $70 \%$ of cardiologists, and $100 \%$ of nephrologists).

Daily HBPM was recommended by $40 \%$ of respondents (highest amongst GPs), while $30 \%$ of physicians (and more specialists) recommended HBPM on 3 days each week (Table 3). The majority of all physicians recommended two measurements during each use of HBPM (Table 3). Almost two-thirds of physicians recommended lifelong HBPM to their patients, although $10 \%-20 \%$ recommended use of HBPM for only one or several months (including one-third of GPs and a quarter of cardiologists) (Table 3). The most common instruction across all specialties was to document all measurements taken during HBPM (Table 3). Consistently across specialties, two-thirds of physicians instructed patients to take morning home BP measurements after 15 minutes of rest, but the majority did not instruct patients to take measurements after micturition and less than half told patients to take their BP before taking antihypertensive medication (Figure 2). 
Table 2 Practice setting and patient comorbidities

\begin{tabular}{llll}
\hline & $\begin{array}{l}\text { GPs } \\
(\mathbf{n = 3 0 )}\end{array}$ & $\begin{array}{l}\text { Cardiologists } \\
(\mathbf{n = 2 0 )}\end{array}$ & $\begin{array}{l}\text { Nephrologists } \\
(\mathbf{n = 1 0 )}\end{array}$ \\
\hline $\begin{array}{llll}\text { Practice setting, } \\
\text { GP (\%) }\end{array}$ & & \\
Group practice & $15(50)$ & 0 & 0 \\
Restructured & $15(50)$ & 0 & 0 \\
Private & 0 & $8(40)$ & $9(90)$ \\
Treated patients by & 0 & $12(60)$ & $1(10)$ \\
No comorbidities & 37 & 17 & \\
Diabetes & 33 & 31 & 16 \\
Hyperlipidemia & 39 & 42 & 53 \\
Stroke & 6 & 13 & 56 \\
Angina & 4 & 31 & 13 \\
Atrial fibrillation & 3 & 18 & 17 \\
Heart failure & 4 & 17 & 12 \\
Myocardial infarction & 5 & 24 & 19 \\
Other & 0 & 1 & 18 \\
\hline
\end{tabular}

Notes: *Total percentages may be $>100 \%$ as patients may have more than one comorbidity.

Abbreviation: GPs, general practitioners.

\section{Ambulatory BP monitoring}

Of the 43 physicians who responded to the relevant questions on ABPM, $72 \%$ said that they would recommend ABPM to their patients; the rate was markedly lower among GPs (50\%) compared with cardiologists (95\%) and nephrologists (90\%). In terms of the proportion of their hypertensive patients who were being recommended to use ABPM, this was $30 \%$ of those treated by GPs, $23 \%$ by cardiologists, and $28 \%$ by nephrologists (27\% overall). All specialties agreed that the most important benefit of ABPM is to provide measurement of BP over 24 hours during normal daily activities that lead to random and cyclical fluctuations in BP (97\% overall, $93 \%$ of GPs, and $100 \%$ of both cardiologists and nephrologists). Just over half felt that ABPM helped to determine the timedependent effects of antihypertensive drugs ( $55 \%$ overall, $57 \%$ of GPs, $55 \%$ of cardiologists, and $50 \%$ of nephrologists), while the proportion of physicians who thought that ABPM assists

Table 3 Recommended frequencies of home blood pressure monitoring and measurements

\begin{tabular}{|c|c|c|c|c|}
\hline \multirow[t]{2}{*}{ Parameter } & \multicolumn{4}{|c|}{ Physicians making recommendation, n (\%) } \\
\hline & Total $(n=60)$ & GPs $(n=30)$ & Cardiologists $(n=20)$ & Nephrologists $(n=10)$ \\
\hline \multicolumn{5}{|l|}{ Frequency of HBPM } \\
\hline Every day & $24(40)$ & $14(47)$ & $8(40)$ & $2(20)$ \\
\hline 5 days every week & $4(7)$ & $3(10)$ & I (5) & $0(0)$ \\
\hline 4 days every week & $6(10)$ & $2(7)$ & $\mathrm{I}(5)$ & $3(30)$ \\
\hline 3 days every week & $18(30)$ & $7(23)$ & $7(35)$ & $4(40)$ \\
\hline 2 days every week & $5(8)$ & $3(10)$ & $\mathrm{I}(5)$ & $I(10)$ \\
\hline I day every week & $3(5)$ & I (3) & $2(10)$ & $0(0)$ \\
\hline \multicolumn{5}{|c|}{ Number of measurements } \\
\hline One & $9(15)$ & $4(13)$ & $3(15)$ & $2(20)$ \\
\hline Two & $41(68)$ & $21(70)$ & $14(70)$ & $6(60)$ \\
\hline Three & $10(17)$ & $5(17)$ & $3(15)$ & $2(20)$ \\
\hline \multicolumn{5}{|l|}{ Duration } \\
\hline Lifelong & $38(63)$ & $18(60)$ & $13(65)$ & $7(70)$ \\
\hline For I year & $2(3)$ & $I(3)$ & $\mathrm{I}(5)$ & $0(0)$ \\
\hline For several months & $10(17)$ & $6(20)$ & $3(15)$ & $I(10)$ \\
\hline For I month & $5(8)$ & $3(10)$ & $2(10)$ & $0(0)$ \\
\hline For I week & $5(8)$ & $2(7)$ & I (5) & $2(20)$ \\
\hline \multicolumn{5}{|c|}{ Measurements to document } \\
\hline All & $23(38)$ & $9(30)$ & $9(45)$ & $5(50)$ \\
\hline Mean of all & $10(17)$ & $5(17)$ & $2(10)$ & $2(20)$ \\
\hline Mean of first and second & $8(13)$ & $4(13)$ & $2(10)$ & $2(20)$ \\
\hline First & $7(12)$ & $5(17)$ & I (5) & $10(10)$ \\
\hline Second & $6(10)$ & $3(10)$ & $3(15)$ & $0(0)$ \\
\hline Mean second and third & $5(8)$ & $2(7)$ & $3(15)$ & $0(0)$ \\
\hline Other & $I(6)$ & $2(7)$ & $0(0)$ & $0(0)$ \\
\hline \multicolumn{5}{|c|}{ Timing of evening measurement } \\
\hline Before dinner & $7(12)$ & I (3) & $6(30)$ & $0(0)$ \\
\hline After dinner & $9(15)$ & $6(20)$ & $2(10)$ & $\mathrm{I}(10)$ \\
\hline Before bedtime & $28(47)$ & $16(53)$ & $4(20)$ & $8(80)$ \\
\hline No instructions & $16(27)$ & $7(23)$ & $8(40)$ & $\mathrm{I}(\mathrm{I0})$ \\
\hline
\end{tabular}

Abbreviations: GPs, general practitioners; HBPM, home blood pressure monitoring. 


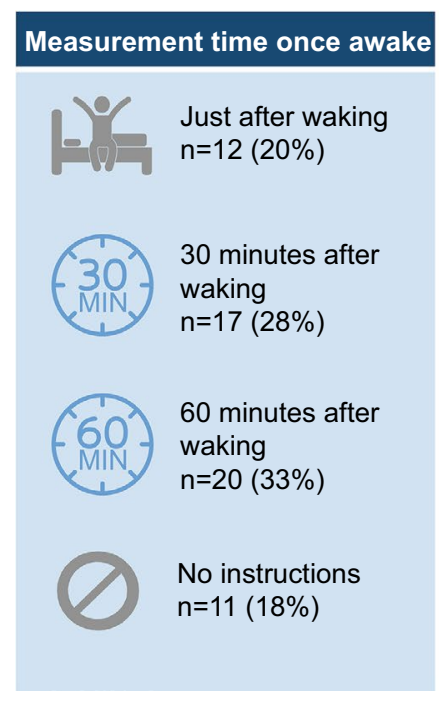

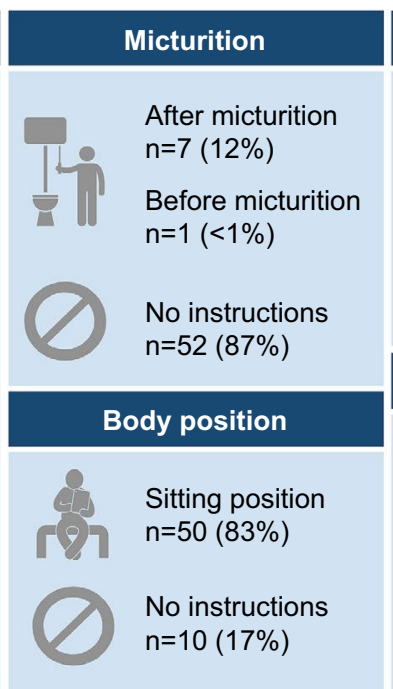

Time of rest before measurement
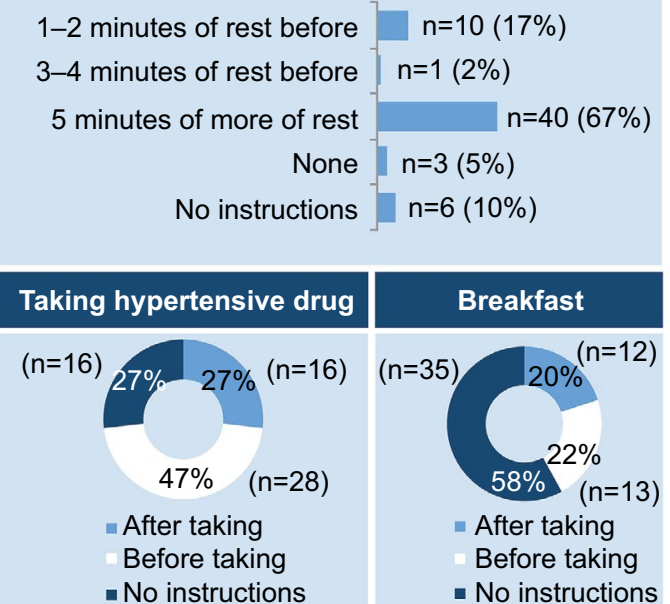

Figure 2 Proportion of physicians providing different instructions for morning home blood pressure measurement to their patients. Note: Values are the percentage of physicians.

\begin{tabular}{|c|c|c|c|c|}
\hline & $\begin{array}{c}\text { OVERALL } \\
(n=59)\end{array}$ & $\begin{array}{c}\text { GPs } \\
(n=15)\end{array}$ & $\begin{array}{c}\text { Cardiologists } \\
(n=19)\end{array}$ & $\begin{array}{c}\text { Nephrologists } \\
(n=9)\end{array}$ \\
\hline Diagnosis of resistant hypertension & $60 \%$ (HBPM 41\%) & $67 \%$ & $63 \%$ & $44 \%$ \\
\hline Confirmation of hypertension & 60 & $53 \%$ & $63 \%$ & $67 \%$ \\
\hline $\begin{array}{r}\text { Evaluation of efficacy antihypertensive drug } \\
\text { efficacy }\end{array}$ & $58 \%$ (HBPM 88\%) & $40 \%$ & $84 \%$ & $33 \%$ \\
\hline Evaluation of blood pressure variability (BPV) & $58 \%$ (HBPM 75\%) & $80 \%$ & $37 \%$ & $67 \%$ \\
\hline Confirmation of BPV from HBPM results & 35 & $33 \%$ & $26 \%$ & $56 \%$ \\
\hline Diagnosis of hypotension & $30 \%$ (HBPM 56\%) & $53 \%$ & $21 \%$ & $11 \%$ \\
\hline Hypertension management based on home BP & $28 \%$ (HBPM 64\%) & $20 \%$ & $37 \%$ & $22 \%$ \\
\hline Improvement of drug compliance & 21\% (HBPM 53\%) & $20 \%$ & $26 \%$ & $11 \%$ \\
\hline Evaluation of patients' CVD risks & 9\% (HBPM 10\%) & $7 \%$ & $5 \%$ & $22 \%$ \\
\hline Others & $7 \%$ (HBPM 2\%) & $0 \%$ & $5 \%$ & $22 \%$ \\
\hline
\end{tabular}

Figure 3 Indications for ABPM overall and by physician specialty; comparative overall values for HBPM are included, where available. Note: Values are the percentage of physicians.

Abbreviations: ABPM, ambulatory blood pressure monitoring; BP, blood pressure; BPV, blood pressure variability; CVD, cardiovascular disease; GPs, general practitioners; HBPM, home blood pressure monitoring.

detection of short-term (every 15-30 minutes) BPV was 32\% (40\% of GPs, $20 \%$ of cardiologists, and $30 \%$ of nephrologists).

The main drivers for recommending ABPM included diagnosis of resistant hypertension, confirmation of hypertension, evaluation of antihypertensive drug efficacy, and confirmation of BPV, with slight variation by specialty (Figure 3); there were also some differences in physician-rated drivers for ABPM vs HBPM (Figure 3).

\section{Challenges in out-of-office BP measurements in clinical practice}

The majority of physicians dedicated one-quarter or less of consultation time to discussing HBPM and BPV with their patients or did not discuss these matters at all (73\% overall, $74 \%$ of GPs, $80 \%$ of cardiologists, and $60 \%$ of nephrologists). When asked whether their team had the ability to provide patients with education on HBPM and BPV during regular clinic work, $55 \%$ of physicians said yes ( $63 \%$ of GPs, $40 \%$ cardiologists, and $60 \%$ of nephrologists). Challenges to the implementation of out-of-office BP measurement cited by equal proportions of physicians overall ( $48 \%$ for each) were patient inertia, poor patient compliance, lack of medical consultation time, and patients not having access to a BP machine, followed by lack of related educational materials ( $45 \%$ of physicians).

\section{Discussion}

The results of our survey showed that nearly all of the surveyed physicians in Singapore recommended HBPM to their 
patients and that HBPM was most commonly recommended for monitoring antihypertensive therapy or BPV. There was no consensus among survey respondents about when and for how long to measure home BP, but there was agreement on the use of two measurements at each time point. Although nearly three-quarters of physicians surveyed said that they would recommend ABPM to their patients, the proportion of patients for whom this actually occurred was much lower (only about one-third). We found that physicians in this study used a small proportion of consultation time to discuss HBPM and BPV with their patients, and almost half of all respondents felt that they did not have the ability to provide patients with education on these topics.

Our results are consistent with those obtained in a survey of Japanese physicians, the majority of whom $(>90 \%)$ recommended HBPM to their patients, but also showed a lack of knowledge of the processes and current local guidelines. ${ }^{10}$ Physicians from Korea have also demonstrated a relatively good awareness of HBPM (78\% recommended HBPM to their patients), but comparatively poor compliance with HBPM guidelines (only 16\% correctly reported all HBPM procedures). ${ }^{11}$ Similar trends have been observed in the Netherlands, where both patients and physicians reported good acceptance of out-of-office BP monitoring, but lower rates of implementation in clinical practice. ${ }^{12}$

HBPM and ABPM are the two currently available options for monitoring BPV. Advantages of ABPM over clinic-based $\mathrm{BP}$ measurement include a greater number of readings, better information on the BP profile during normal daily activities, assessment of BPV and the 24-hour effectiveness of antihypertensive medication, and better prediction of cardiovascular morbidity and mortality. ${ }^{2}$ With HBPM, multiple readings under standardized conditions can be obtained over long periods of time. ${ }^{13}$ The ability to take measurements under similar conditions every day means that HBPM has greater reproducibility than ABPM. ${ }^{13}$

According to Japanese hypertension guidelines, HBPM is preferred for the evaluation of BPV over an extended period. ${ }^{4}$ Either ABPM or HBPM may be considered for out-of-office BP measurements in the European guidelines, with the choice of approach based on indication, availability, ease, cost of use, and possibly also patient preference. ${ }^{14}$ The two monitoring approaches provide slightly different information on both BP and risk, and are therefore seen as complementary, rather than competitive. ${ }^{14}$ However, some believe that HBPM should be the monitoring tool of choice and that this should take the leading role in hypertension management. ${ }^{13}$ The findings of a meta-analysis looking at the association between $\mathrm{BP}$ determined using HBPM or ABPM and mortality support guideline recommendations to include HBPM for clinical practice management of patients with hypertension. ${ }^{15}$ In addition, HBPM has been shown to improve BP control ${ }^{16}$ and adherence to antihypertensive medication. ${ }^{17}$ Physician attitudes also have the potential to influence the differential uptake of ABPM and HBPM. In a study conducted in the Netherlands, physicians showed a strong preference for ABPM over HBPM, which influenced the uptake and use of these approaches by patients. ${ }^{12}$

In our study, HBPM was more widely used and recommended than ABPM by GPs, probably because this is a more accessible option. ABPM in Singapore is expensive and not widely available, limiting uptake and use. This reflects data suggesting that the widespread incorporation of ABPM into routine clinical practice is limited by lower acceptability, tolerability, reproducibility, and reliability compared with HBPM, as well as higher costs. ${ }^{13}$ Both cost and convenience have been cited as reasons why ABPM is not routinely recommended as part of hypertension management. ${ }^{18,19}$ In contrast, specialists who responded to our survey were more likely to recommend ABPM than HBPM, and nearly twice as likely to recommend ABPM to their patients than GPs. This may reflect the fact that specialists see more patients with comorbidities than GPs, and recognize that BPV is an important prognostic factor in this patient group. In hypertensive patients with kidney disease, BP values obtained using ABPM have been shown to predict mortality better than BP measured using HBPM or in the clinic. ${ }^{20}$

To provide important and accurate data on BPV, the approach to measuring home BP needs to be standardized, ${ }^{21}$ and any form of out-of-office BP measurement should be performed using a validated device. ${ }^{3,22}$ Variations in the timing and frequency of HBPM across studies have been reported, whereas ABPM tends to be used more consistently. ${ }^{15}$ The results of our survey indicated considerable variation between physicians in the processes and recommendations for home $\mathrm{BP}$ assessment. The JSH has provided detailed guidance on measurement of morning HBPM since 2003. ${ }^{22}$ These guidelines state that morning home BP should be measured within 1 hour after waking, after micturition, in a sitting position, after 1-2 minutes of rest, and before taking any antihypertensive drugs and breakfast. ${ }^{22}$ The relatively high number of physicians in our survey not providing HBPM instructions regarding micturition or about the timing of measurements may indicate a gap in knowledge. Controlling the timing of evening measurements is more difficult when compared with morning measurements. To improve compliance with 
measurement of home BP, only a single condition (measurement just before bedtime) was proposed by JSH. ${ }^{22}$ The majority of physicians in our survey recommended that patients took two measurements of home BP at each assessment, consistent with the NICE and JSH guidelines. ${ }^{3,4}$ Also, a significant proportion of physicians (40\% of GPs, 35\% of cardiologists, and 30\% of nephrologists) indicated that the recommended duration for undertaking HBPM was not lifelong $(20 \%, 15 \%$, and $10 \%$, respectively, only suggested patients do HBPM for just "several months"). This may also be indicative of knowledge gaps.

Another finding of interest was the low proportion of cardiologists $(37 \%)$ who considered evaluation of BPV as an indication for ABPM. BPV has been associated with increased cardiovascular risk, ${ }^{6}$ and ABPM has been described as the gold standard for predicting risk related to $\mathrm{BP} .^{23}$ Therefore, it might have been expected that cardiologists would be the group of surveyed physicians who were most aware of the need to monitor ambulatory readings. We also found that the proportion of consultation time dedicated to discussing HBPM and BPV was low and that some physicians did not address these topics at all. Lack of physician knowledge could contribute to physicians' inability to provide patients with education about out-of-office BP monitoring and BPV, with almost half saying that their team did not have this capability. European guidelines state that ABPM or HBPM procedures need to be adequately explained to the patient, with written and verbal instructions, as well as supervised training. ${ }^{1}$ The high patient refusal rate for both ABPM and HBPM reported in our survey may reflect a lack of information provided to patients by physicians. The knowledge gaps identified suggest that the use of ABPM and HBPM by patients could be improved by better physician training.

Our survey provides useful data on local clinical practice relating to out-of-office BP monitoring in Singapore, including identification of a number of important unmet needs and knowledge gaps. However, there are a number of limitations. First, the study has a cross-sectional, nonrandomized design, meaning that there is the potential for bias to influence the findings. In addition, the number of physicians who responded to our survey was small and the possibility that physicians who chose not to participate may have answered questions differently cannot be excluded. The proportion of physicians contacted who responded, agreed to participate, and qualified screening was lowest for GPs (20\%) compared with cardiologists $(46 \%)$ or nephrologists $(50 \%)$. The reasons for this are unclear, but time available within busy clinical practice and less of a specific focus on patients with hypertension may have contributed (e.g., not all GPs saw $>30$ patients with hypertension per month, whereas all specialists did). In addition, the eligible GPs and cardiologists who completed the survey tended to be in private practice, which may not reflect practices under the public health system.

\section{Conclusion}

Although the majority of Singapore GPs, cardiologists, and nephrologists surveyed recommended the use of HBPM for the management of patients with hypertension, the findings of this survey identified several potential gaps in knowledge and clinical practice in relation to current international guidelines. Better physician education and training could help address these unmet needs and overcome barriers to the use of ABPM and HBPM in Singapore.

\section{Acknowledgments}

The authors would like to thank the management and staff of Kantar Health, Singapore, for their efforts in screening the respondents and carrying out interviews with the eligible respondents. Editorial and medical writing support was provided by Nicola Ryan, independent medical writer, funded by Pfizer.

Pfizer, Singapore funded this survey. Pfizer did not fund any medicines or devices for the conduct of this survey.

\section{Author contributions}

Dr Sajita Setia and Dr Kannan Subramaniam were involved in conception, design, analysis, and the interpretation of data. Dr Boon Wee Teo and Professor Jam Chin Tay were involved in the analysis and interpretation of data. All authors were involved in the preparation of the manuscript, the revision of it for important intellectual content, and its final approval before submission for publication.

\section{Disclosure}

Dr Sajita Setia and Dr Kannan Subramaniam are employees of Pfizer. Professor Jam Chin Tay has received advisory board and consultant honoraria from Pfizer. The authors report no other conflicts of interest in this work.

\section{References}

1. Mancia G, Fagard R, Narkiewicz K, et al. 2013 ESH/ESC practice guidelines for the management of arterial hypertension. Blood Press. 2014;23(1):3-16.

2. O'Brien E, Parati G, Stergiou G, et al. European Society of Hypertension position paper on ambulatory blood pressure monitoring. J Hypertens. 2013;31(9):1731-1768.

3. National Institute for Health and Care Excellence. Hypertension: clinical management of primary hypertension in adults (update). Clinical guideline 127 (2011). Available from: https://www.nice.org.uk/guidance/cg127/chapter/1-guidance. Accessed December 15, 2016. 
4. Shimamoto K, Ando K, Fujita T, et al. The Japanese Society of Hypertension Guidelines for the Management of Hypertension (JSH 2014). Hypertens Res. 2014;37(4):253-390.

5. Parati G, Stergiou G, O’Brien E, et al. European Society of Hypertension practice guidelines for ambulatory blood pressure monitoring. J Hypertens. 2014;32(7):1359-1366.

6. Stevens SL, Wood S, Koshiaris C, et al. Blood pressure variability and cardiovascular disease: systematic review and meta-analysis. BMJ. 2016;354:i4098.

7. James PA, Oparil S, Carter BL, et al. 2014 evidence-based guideline for the management of high blood pressure in adults: report from the panel members appointed to the Eighth Joint National Committee (JNC 8). JAMA. 2014;311(5):507-520.

8. Singapore Ministry of Health. Ministry of Health (MOH) Clinical Practice Guidelines 2/2005: Hypertension (including withdrawal notice). Available from: https://www.moh.gov.sg/content/dam/moh_web/HPP/ Doctors/cpg_medical/withdrawn/cpg_Hypertension-Jun 2005.pdf. Accessed February 20, 2017.

9. Singapore Ministry of Health. Biomedical Research Regulation. Operational Guidelines for Institutional Review Boards. Dec 2007. Available from: https://www.moh.gov.sg/content/dam/moh_web/Publications/Guidelines/Human Biomedical Research/2007/IRB Operational Guidelines_14-12-07_formatted.pdf. Accessed May 26, 2017.

10. Obara T, Ohkubo T, Fukunaga H, et al. Practice and awareness of physicians regarding home blood pressure measurement in Japan. Hypertens Res. 2010;33(5):428-434.

11. Kim DY, Kim SH, Kim HJ, Jung SM, Ryu KH. Physician's awareness and education for patient on life style modification and home blood pressure monitoring recommended in hypertension guideline. J Korean Soc Hypertens. 2012;18:97-104.

12. Carrera PM, Lambooij MS. Implementation of out-of-office blood pressure monitoring in the Netherlands: from clinical guidelines to patients' adoption of innovation. Medicine (Baltimore). 2015;94(43):e1813.

13. Imai Y, Obara T, Asamaya K, Ohkubo T. The reason why home blood pressure measurements are preferred over clinic or ambulatory blood pressure in Japan. Hypertens Res. 2013;36(8):661-672.
14. Mancia G, Fagard R, Narkiewicz K, et al. 2013 ESH/ESC guidelines for the management of arterial hypertension: the Task Force for the management of arterial hypertension of the European Society of Hypertension $(\mathrm{ESH})$ and of the European Society of Cardiology (ESC). Eur Heart J. 2013;34(28):2159-2219.

15. Breaux-Shropshire TL, Judd E, Vucovich LA, Shropshire TS, Singh S. Does home blood pressure monitoring improve patient outcomes? A systematic review comparing home and ambulatory blood pressure monitoring on blood pressure control and patient outcomes. Integr Blood Press Control. 2015;8:43-49.

16. Cappuccio FP, Kerry SM, Forbes L, Donald A. Blood pressure control by home monitoring: meta-analysis of randomised trials. BMJ. 2004;329(7458): 145 .

17. Ogedegbe GO, Boutin-Foster C, Wells MT, et al. A randomized controlled trial of positive-affect intervention and medication adherence in hypertensive African Americans. Arch Intern Med. 2012;172(4):322-326

18. Mancia G, Bombelli M, Brambilla G, et al. Long-term prognostic value of white coat hypertension: an insight from diagnostic use of both ambulatory and home blood pressure measurements. Hypertension. 2013;62(1): 168-174.

19. Weber MA, Schiffrin EL, White WB, et al. Clinical practice guidelines for the management of hypertension in the community a statement by the American Society of Hypertension and the International Society of Hypertension. J Hypertens. 2014;32(1):3-15.

20. Agarwal R, Andersen MJ. Blood pressure recordings within and outside the clinic and cardiovascular events in chronic kidney disease. $\mathrm{Am} \mathrm{J}$ Nephrol. 2006;26(5):503-510.

21. Sharman JE, Howes F, Head GA, et al. How to measure home blood pressure: recommendations for healthcare professionals and patients. Aust Fam Physician. 2016;45(1):31-34.

22. Imai Y, Otsuka K, Kawano Y, et al. Japanese society of hypertension (JSH) guidelines for self-monitoring of blood pressure at home. Hypertens Res. 2003;26(10):771-782.

23. Pickering TG, Shimbo D, Haas D. Ambulatory blood-pressure monitoring. N Engl J Med. 2006;354(22):2368-2374.
International Journal of General Medicine

\section{Publish your work in this journal}

The International Journal of General Medicine is an international, peer-reviewed open-access journal that focuses on general and internal medicine, pathogenesis, epidemiology, diagnosis, monitoring and treatment protocols. The journal is characterized by the rapid reporting of reviews, original research and clinical studies across all disease areas.

\section{Dovepress}

The manuscript management system is completely online and includes a very quick and fair peer-review system, which is all easy to use. Visit http://www.dovepress.com/testimonials.php to read real quotes from published authors. 